\title{
New insights into thyroid hormone replacement therapy
}

\section{Brenda M Acosta* and Antonio C Bianco}

\author{
Address: Division of Endocrinology, Diabetes and Metabolism, University of Miami Miller School of Medicine, 1450 NW $10^{\text {th }}$ Avenue \#3054, \\ Miami, FL 33136, USA \\ *Corresponding author: Brenda M Acosta (bacosta3@med.miami.edu) \\ FI000 Medicine Reports 2010, 2:34 (doi:10.3410/M2-34)
}

The electronic version of this article is the complete one and can be found at: http://fl000.com/reports/medicine/content/2/34

\begin{abstract}
It is widely accepted that thyroid hormone replacement for patients with hypothyroidism can be fully accomplished with levothyroxine monotherapy, as assessed by serum thyroid function tests. However, approximately 10\% of hypothyroid patients are dissatisfied with the outcome of levothyroxine monotherapy, and physicians continue to report benefits from combined levothyroxine-triidothyronine therapy for some hypothyroid patients. Recently, a large prospective study reported that the benefit of the combined levothyroxine-triidothyronine therapy is associated with the Thr92Ala polymorphism in the type 2 deiodinase gene, which is present in about $15 \%$ of the general population. If confirmed, these findings indicate that personalized medicine is rapidly catching up with modern thyroidology.
\end{abstract}

\section{Introduction and context}

Hypothyroidism is one of the most common endocrine disorders, affecting about $4 \%$ of the adult US population [1], and is caused primarily by autoimmune thyroiditis. Even though it is recognized that 3,5,3'-triiodothyronine (T3) is the biologically active form of thyroid hormone, for decades replacement therapy has been based on levothyroxine (L-T4) monotherapy [2]. This rationale stems from the existence of iodothyronine deiodinases, enzymes that activate thyroxine (T4) to T3 outside of the thyroid parenchyma and generate most of the circulating T3 [3]. However, large community-based studies have reported that a subset (about 10\%) of hypothyroid patients on L-T4 monotherapy exhibit significant impairment in psychological well-being, even when serum thyroid function tests are within the normal range $[4,5]$. This suggests that these important neurocognitive parameters may not be completely restored in these hypothyroid patients when kept on L-T4 monotherapy. These findings create the need for alternative therapeutic approaches for hypothyroid patients that do not do well on L-T4 monotherapy, including the use of desiccated animal thyroid or combined therapy with L-T4 and 3,5,3'-L-triiodothyronine (L-T3) (T4/T3). In the latter case, studies have been hampered due to formulation issues, given that T4 has a much longer half-life and the current lack of a long acting preparation of L-T3.

T3 and T4 are found at a ratio of approximately 1:15 in the human thyroglobulin molecule [6], and this is unlikely to be markedly affected by the intrathyroidal conversion of T4 to T3. Thus, one would think that in order to mimic normal thyroidal secretion, thyroid hormone replacement therapy should be based on the combination of L-T4 and L-T3 at similar ratios as found in human thyroglobulin. However, for decades it has been known that $\mathrm{T} 4$ can be activated outside the thyroid gland to T3 via iodothyronine deiodinases D1 and D2. These are highly homeostatic enzymes that adjust their catalytic activities according to the plasma levels of T4 and T3. In fact, this paradigm is supported by extensive literature that has served as the basis for the guidelines set forth by the American Thyroid Association recommending L-T4 monotherapy as the primary choice for thyroid hormone replacement in patients with hypothyroidism [7]. 
A meta-analysis of 11 randomized controlled trials with a total of 1216 patients indicated that T4/T3 combination therapy provided no advantage when compared with standard L-T4 monotherapy in any of the following parameters: bodily pain, depression, anxiety, fatigue, quality of life, body weight, total serum cholesterol and triglycerides, serum low-density lipoprotein, and highdensity lipoprotein, and demonstrated no difference in adverse events [8]. A second meta-analysis including a total of 1243 patients suggested that T4/T3 combination therapy is beneficial for the psychological and physical well-being of patients previously on L-T4 monotherapy, but there was no statistically significant difference in the other variables [9]. Only one trial found a significant benefit of T4/T3 combination therapy compared with L-T4 monotherapy [10], but it is not clear whether these findings were related to the cause of hypothyroidism, as was later suggested [11].

\section{Recent advances}

It is well accepted that, in humans, most circulating T3 is derived from extrathyroidal deiodination of T4 via D2 [3]; thus, it makes sense to hypothesize that defects in D2 expression/activity could interfere with the efficacy of L-T4 monotherapy. In recent years, several polymorphisms have been reported for the gene encoding D2 (DIO2), including some associated with insulin resistance, obesity [12], and hypertension [13], to name but a few. However, these findings have been restricted to specific populations and a more universal corollary is still missing. Central to this problem is whether any of the DIO2 polymorphisms reported to date affect the activity and/or kinetic properties of D2. The single nucleotide polymorphism A/G in DIO2 predicts a threonine to alanine substitution at codon 92 (Thr92Ala) and, in subjects homozygous for the Ala allele, D2 velocity was reported to be decreased in an early study [14], but this may have been the result of an artifact [15].

With this in mind, Panicker et al. [16] asked whether common variants in $\mathrm{DIO} 2$ could explain differences in psychological morbidity and response to thyroid hormone replacement therapy in 552 patients of the Weston Area T4/T3 Study (WATTS) in the UK. Their results indicated that the Thr92Ala polymorphism in DIO2 is associated with both impaired baseline psychological well-being in patients on L-T4 monotherapy and enhanced response to combination T4/T3 therapy, which could explain the biological mechanism of the T3 requirement.

However, what could be the mechanistic basis for such findings given that the DIO2 polymorphism did not affect thyrotropin, T4, or T3 serum levels in the Panicker et al. study? A rationale could be based on the fact that
D2 activity increases the intracellular T3 concentration relatively independently of the serum concentration of T3 [3]. Accordingly, DIO2 knockout mice have normal serum T3 concentrations but only half as much T3 in their brains as wild type [17]. Although not as severe as in hypothyroid mice, the DIO2 knockout mice exhibited clear defects in certain agility tasks when evaluated for locomotion and agility, learning and memory, reflexes, anxiety, and exploratory levels. Furthermore, these animals are also known for exhibiting defects in adaptive thermogenesis and thermal homeostasis because of the role played by $\mathrm{D} 2$ in brown adipose tissue $[18,19]$. Whether these findings could serve as the basis for the improved psychological well-being and quality of life reported in patients receiving combination T4/T3 therapy remains to be determined.

\section{Implications for clinical practice}

The overwhelming evidence available in the literature supports the notion that L-T4 monotherapy provides adequate thyroid hormone replacement in patients with hypothyroidism. A small subset of hypothyroid patients does seem to have a better quality of life and perform better on cognitive tests when placed on combination T4/T3 therapy. According to one large study, this could be explained by the Thr92Ala polymorphism in the DIO2 gene, which is present in about $15 \%$ of the general population. While a prospective trial studying the effect of the Thr92Ala polymorphism on the neuropsychiatric response to combined T3/T4 versus L-T4 monotherapy has yet to be carried out, it is fascinating to contemplate the notion that personalized medicine is rapidly catching up with modern thyroidology.

\section{Abbreviations}

D2, iodothyronine deiodinase type 2; L-T3, 3,5,3'L-triiodothyronine; L-T4, levothyroxine; T3, 3,5,3'triiodothyronine; $\mathrm{T} 4$, thyroxine.

\section{Competing interests}

The authors declare that they have no competing interests.

\section{Acknowledgments}

The authors are partially supported by National Institute of Diabetes and Digestive and Kidney Diseases grants.

\section{References}

I. Aoki Y, Belin RM, Clickner R, Jeffries R, Phillips L, Mahaffey KR: Serum TSH and total T4 in the United States population and their association with participant characteristics: National Health and Nutrition Examination Survey (NHANES 19992002). Thyroid 2007, 17:1211-23.

2. Brent GA, Larsen PR, Davies T: Hypothyroidism and thyroiditis. In Williams Textbook of Endocrinology. I I th edition. Edited by 
Kronenberg HM, Melmed S, Polonsky KS, Larsen PR. Philadelphia: WB Saunders Company; 2008:377-409.

3. Gereben B, Zavacki A, Ribich S, Kim B, Huang S, Simonides W, Zeöld A, Bianco A: Cellular and molecular basis of deiodinaseregulated thyroid hormone signaling. Endocr $\operatorname{Rev} 2008,29: 898-$ 938.

4. Wekking EM, Appelhof BC, Fliers E, Schene AH, Huyser J, Tijssen JG, Wiersinga WM: Cognitive functioning and well-being in euthyroid patients on thyroxine replacement therapy for primary hypothyroidism. Eur J Endocrinol 2005, I 53:747-53.

5. Saravanan P, Chau WF, Roberts N, Vedhara K, Greenwood R, Dayan CM: Psychological well-being in patients on 'adequate' doses of I-thyroxine: results of a large, controlled communitybased questionnaire study. Clin Endocrinology 2002, 57:577-85.

6. Izumi M, Larsen PR: Triiodothyronine, thyroxine, and iodine in purified thyroglobulin from patients with Graves' disease. J Clin Invest 1977, 59: I 105-12.

7. Singer PA, Cooper DS, Levy E, Ladenson PW, Braverman LE, Daniels G, Greenspan FS, McDougall R, Nikolai TF: Treatment guidelines for patients with hyperthyroidism and hypothyroidism. J Am Med Assoc 1995, 273:808-12.

8. Grozinsky-Glasberg S, Fraser A, Nahshoni E, Weizman A, Leibovici L: Thyroxine-triiodothyronine combination therapy versus thyroxine monotherapy for clinical hypothyroidism: metaanalysis of randomized controlled trials. J Clin Endocrinol Metab 2006, $91: 2592-9$.

9. Ma C, Xie J, Huang X, Wang G, Wang Y, Wang X, Zuo S: Thyroxine alone or thyroxine plus triiodothyronine replacement therapy for hypothyroidism. Nucl Med Commun 2009, 30:586-93.

10. Bunevicius R, Kazanavicius G, Zalinkevicius R, Prange AJ Jr: Effects of thyroxine as compared with thyroxine plus triiodothyronine in patients with hypothyroidism. New Engl J Med 1999, 340:424-9.

II. Bunevicius R, Jakubonien N, Jurkevicius R, Cernicat J, Lasas L, Prange AJ Jr: Thyroxine vs thyroxine plus triiodothyronine in treatment of hypothyroidism after thyroidectomy for Graves' disease. Endocrine 2002, 18:129-33.

12. Mentuccia D, Proietti-Pannunzi L, Tanner K, Bacci V, Pollin TI, Poehlman ET, Shuldiner AR, Celi FS: Association between a novel variant of the human type 2 deiodinase gene Thr92Ala and insulin resistance: evidence of interaction with the Trp64Arg variant of the beta-3-adrenergic receptor. Diabetes 2002, 5I:880-3.

13. Gumieniak O, Perlstein TS, Williams JS, Hopkins PN, Brown NJ, Raby BA, Williams GH: Ala92 type 2 deiodinase allele increases risk for the development of hypertension. Hypertension 2007, 49:46I-6.

14. Canani LH, Capp C, Dora JM, Meyer EL, Wagner MS, Harney JW, Larsen PR, Gross JL, Bianco AC, Maia AL: The type 2 deiodinase A/G (Thr92Ala) polymorphism is associated with decreased enzyme velocity and increased insulin resistance in patients with type 2 diabetes mellitus. J Clin Endocrinol Metab 2005, 90:3472-8.

15. Larsen PR: Type 2 iodothyronine deiodinase in human skeletal muscle: new insights into its physiological role and regulation. J Clin Endocrinol Metab 2009, 94:1893-5.

16. Panicker V, Saravanan P, Vaidya B, Evans J, Hattersley AT, Frayling TM, Dayan CM: Common variation in the DIO2 gene predicts baseline psychological well-being and response to combination thyroxine plus triiodothyronine therapy in hypothyroid patients. J Clin Endocrinol Metab 2009, 94:1623-9.

FI000 Factor 3.0 Recommended

Evaluated by John Walsh 29 May 2009

17. Galton VA, Wood ET, St Germain EA, Withrow CA, Aldrich G, St Germain GM, Clark AS, St Germain DL: Thyroid hormone homeostasis and action in the type 2 deiodinase-deficient rodent brain during development. Endocrinology 2007, I 48:3080-8.

18. Christoffolete MA, Linardi CC, de Jesus L, Ebina KN, Carvalho SD, Ribeiro MO, Rabelo R, Curcio C, Martins L, Kimura ET, Bianco AC: Mice with targeted disruption of the Dio2 gene have coldinduced overexpression of the uncoupling protein I gene but fail to increase brown adipose tissue lipogenesis and adaptive thermogenesis. Diabetes 2004, 53:577-84.

19. de Jesus LA, Carvalho SD, Ribeiro MO, Schneider M, Kim SW Harney JW, Larsen PR, Bianco AC: The type 2 iodothyronine deiodinase is essential for adaptive thermogenesis in brown adipose tissue. J Clin Invest 200I, I08:1379-85. 